avalia pelo dano que a falta do atendimento gera e aquelas pessoas que se socorrem dos serviços públicos educacionais não têm outras alternativas para tal atendimento e, ainda, se as possibilidades de alteração/ passam necessariamente pelo incremento do nível educacional, ora, então há sentida injustiça social nas políticas de educação infantil na RMCL.

\section{Bibliografia}

FIGUEIREDO, A. Princípios de justiça e avaliação de políticas. Lua Nova. Revista de Cultura e Política. 1997, n³9, CEDEC

GOUVEIA, A. \& SOUZA, A. O financiamento da educação em municípios da região metropolitana de Curitiba/PR/Brasil: os desafios frente à expansão da oferta numa região em crescimento. Scripta Nova: Revista electrónica de geografía y ciencias sociales. 2005.

Vol. 9: Los agentes urbanos y las políticas sobre la ciudad. Número extraordinario dedicado al VII Coloquio Internacional de Geocrítica (Actas del Coloquio). Barcelona. Disponível em http:// www.ub.es/geocrit/sn/sn-194-64.htm.

Instituto Nacional de Estudos e Pesquisas Educacionais Anísio Teixeira - INEP (www.inep.gov.br). Instituto Brasileiro de Geografia e Estatística - IBGE (www.ibge.gov.br).

Instituto Paranaense de Desenvolvimento Econômico e Social - IPARDES (www.ipardes.gov.br).

ROSEMBERG, F. Expansão da Educação Infantil e Processos de Exclusão. Cadernos de Pesquisa, n. 107, p.7-40, julho/1999.

O estado dos dados para avaliar políticas de educação Infantil.

Estudos em Avaliação Educacional. n² 20, jul-dez/1999.

Recebido em agosto de 2007

Aprovado em setembro de 2007

RESENHA

\title{
SANDER, BENNO. Administração da Educação no Brasil: Genealogia do Conhecimento. Brasília: Liber Livro, 2007.
}

Por Luiza Freire Noguchi

O campo da Administração Escolar ou Gestão Escolar, como é abordado na atualidade, teve diversos estudos sistemáticos de educadores brasileiros, no decorrer do século $\mathrm{XX}$, na tentativa de elaborar conceitos teóricos e dar-Ihe significado. Estes estudos se deram pela necessidade emergencial de organização técnica, pedagógica e administrativa nas ações das organizações escolares.

São identificáveis três momentos históricos de reflexões sobre a práxis neste campo: um primeiro momento (início do século XX até meados dos anos 70) é o de sistematização do conhecimento acerca do campo de caráter mais técnico e pragmático; um segundo momento de crítica aos modelos das décadas anteriores que se inicia concomitante aos movimentos de redemocratização política dos anos 80 e finalmente o atual momento, de novas configurações para o campo sob o signo de gestão, a partir da década de 90 e à luz das novas configurações do capitalismo em âmbito mundial.

É no contexto de crítica aos modelos anteriores, iniciado em meados dos anos 80, que Benno Sander lança em 1982 a primeira versão de Administração da Educação no Brasil: Genealogia do
Conhecimento, entretanto após diversas publicações, agregou outras reflexões $e$ apontamentos sobre o tema e relançou obra em 2007, com a coerente justificativa "de que aquilo que sabíamos ontem já não é suficiente hoje" (SANDER, 2007, p.7).

O objetivo do autor é ensaiar sobre o que ele denomina "paradigma multidimensional da administração da educação" (idem, p.9), ou seja, dimensionar as várias faces que compõe o conceito e a prática da administração escolar. Sendo assim, o autor estruturou sua obra em três capítulos: no primeiro detém-se na introdução à genealogia do conhecimento da administração escolar ao longo da história brasileira; no segundo capítulo constró de maneira extremamente didática quatro modelos de gestão da educação, à luz da história analisada no capítulo anterior e finalmente no terceiro capítulo ensaia "uma perspectiva analítica e praxiológica de gestão educacional" (SANDER, 2007, p.8) com o objetivo de dimensionar e conceituar o paradigma anteriormente citado.

Para o autor só é possível a compreensão do campo da administração escolar, tendo em vista que "a gestão da educação, longe de ser um instrumento ideologicamente neutro, desempenha um papel político e cultural 
específico, situado no tempo e no espaço" (idem, p.14) para isso faz-se necessária a apreensão do movimento histórico e os critérios que configuram o campo.

Logo no primeiro capítulo, o autor prioriza uma análise sobre a genealogia histórica da administração escolar, centrando na análise das condições históricas do campo em três grandes períodos - o Brasil Colônia, a República chegando até meados da década de 60-70 do século XX e o Brasil da atualidade. Partindo da reflexão que as teorias e modelos administrativos nacionais são importações dos modelos estrangeiros como "esforço de criação de soluções teóricas e metodológicas nacionais" (SANDER, 2007 p.12), o autor destaca com objetividade as características legalistas, positivistas e funcionalistas dos primeiros períodos históricos, onde a concepção advinda do direito romano permeou a concepção e a prática da administração escolar da época.

A primeira fase do período republicano perpetuou o sentido positivista da administração escolar e agregou os preceitos de ordem e progresso nas práticas administrativas, no sentido de manter a ordem e o desenvolvimento das organizações escolares. Já na segunda fase, Sander indica a trajetória da administração escolar aderente à administração pública, neste ponto o autor considera quatro fases que correspondem a cada modelo específico de gestão denominados "organizacional, comportamental, desenvolvimentista e sociocultural' (idem, p.26) definidos por critérios de desempenho administrativos: eficiência, eficácia, efetividade e relevância

Neste ponto o autor alia o percurso histórico que priorizou na abordagem deste capítulo à contextualização das quatro fases. A exposição é feita de forma didática enfatizando as origens das fases e o como se deu a realização destas na administração escolar no Brasil. Cita também os autores que tiveram relevância na produção da época como Anísio Teixeira, José Querino Ribeiro Manoel B. Lourenço Filho e Myrtes Alonso. Estes autores são referências substanciais para o entendimento dos conceitos das três primeiras fases expostas por Sander.

A evolução e a importância das mudanças mostradas pele autor, através das décadas, na forma como as escolas aderiam aos modelos de gestão foi exposta com inúmeros exemplos de estudos vinculados à construção dos modelos que são realizados pela própria sociedade. A apreensão deste movimento está muito presente principalmente quando o autor ensaia sobre a administração na contemporaneidade:

foi, precisamente, a convicção da importância das lições do passado para interpretar as condições e necessidades do presente que me levou a fazer este exercício de desconstrução da experiência este exercicio de desconstrução da experiência
historicamente acumulada em matéria de historicamente acumulada em materia de
administração educacional (SANDER, 2007, p.59).

Ao finalizar este capítulo, o autor destaca a importância das décadas de 1980 e 1990 na produção de estudos que contemplem a administração escolar, para que possam ser encontradas perspectivas de reconstruções teóricas neste campo, cita algumas produções de autores dos anos 80 (Arroyo, Frigotto, Felix Rosar, entre outros) e dos anos 90 (Souza, Wittman e Gracindo) que se debruçaram sobre os temas neste campo, como a gestão democrática assunto recorrente e primordial nos debates da atualidade.

O segundo capítulo é caracterizado pela abordagem dos conceitos dos modelos de administração daeducação deformabastante instrumental e didática, como ademais o faz na totalidade da obra. Segundo Sander, esta forma de apresentação "oferece elementos para a construção de contornos conceituais e analíticos de quatro correspondentes modelos de gestão da educação" (SANDER, 2007, p.73) e que o "critério de desempenho administrativo traduz a orientação teleológica adotada na concepção e no exercício da administração" (idem, p.74).

Os modelos são apresentados e caracterizados resumidamente da seguinte forma:

eficiência - critério econômico que traduz capacidade administrativa de produzir o máximo de resultados como mínimo de recursos, energia e tempo; eficácia -é o critério institucional que revela a capacidade administrativa para alcançar metas estabelecidas ou resultados propostos; efetividade - critério político que reflete capacidade administrativa para satisfazer as demandas concretas feitas pela comunidade (...) refletindo a capacidade de resposta às exigências da sociedade; relevância - critério cultural que mede 0 desempenho administrativo em termos de importância, significação, pertinência e valor de importância, significação, pertinência e valor sua atuação para a melhoria do desenvolvimento humano e da qualidade de vida na escola e na sociedade (SANDER, 2007, p.75-83).

Estes conceitos são agregados às discussões anteriores sobre os modelos de gestão historicamente determinados. Segundo as análises do autor; cada critério de desempenho administrativo foi relacionado neste segundo capítulo a um modelo, por isso o caráter instrumental da análise. Um paradoxo neste capítulo é a desvinculação do conceito de efetividade com o de relevância. O autor reflete que a abordagem do ensaio centra-se naquestão cultural-queéligadaao conceito de relevância - justificando assim que o conceito de efetividade está mais relacionado ao de política. Neste ponto reside o paradoxo, uma vez que é inviável desligar a política da cultura já que os dois são produtos da humanidade, determinados pelos sujeitos e estão em freqüente aderência. Eis um tema que poderia ser revisitado e aprofundado neste livro, pois a efetividade como critério de atendimento às demandas sociais está intrinsecamente ligada à idéia de relevância, já que se trata de efetiva melhoria na qualidade de vida dos sujeitos, configurando-se desta maneira como pares e não como critérios separados.

No terceiro e último capítulo, Sander conclui à luz das análises históricas aliadas aos critérios de desempenho econômico, a possível apresentação do "paradigma multidimensional de administração da educação", que é um esforço de construção e desconstrução de conceitos sobre a prática da administração escolar tomando como base um enfoque multiparadigmático: "a proposta é elaborar uma nova síntese teórica da prática da administração da educação, baseada em uma visão de simultaneidade dos atos e fatos administrativos" (SANDER 2007, p.91). De maneira didática novamente o autor exemplifica que esta proposta possível através de quatro dimensões simultâneas e articuladas: econômica, pedagógica, política e cultural. Também correspondem estas aos critérios de desempenho administrativo anteriormente citados, entretanto com uma "orientação antropossociopolítica (...) a eficiência é subsumida pela eficácia; a eficácia e a eficiência são subsumidas pela efetividade; e a efetividade, a eficácia e a eficiência são subsumidas pela relevância" (idem, p.106).

É interessante a colocação de Sander que no ambiente escolar todas estas dimensões estãointrinsecamentearticuladas, oquepode ser considerado um avanço nas discussões do campo da administração escolar, que por muitas vezes, desagregava estes fatores e analisava algumas dimensões como se 
estas correspondessem à totalidade. O autor conclui seu ensaio apontando:

administração desempenha um pape mediador, essencial, substantivo, dialógico que determina, significativamente, a própria natureza das interaç̃os múltiplas e simultâneas que ocorrem no sistema educacional, suas escolas e universidades. Na realidade, mediação administrativa não está a serviço do processo educacional: ela é parte do processo (idem, p.108).

Paraoautor, apreendertodaacomplexidade da multidimensionalidade da administração escolaréum desafio àcomunidade acadêmica e pode se dar pela formação de docentes e gestores escolares, sendo que estes devem ter contempladas em sua formação, quatro qualificações básicas ligadas às dimensões já abordadas anteriormente.

Como a obra foi atualizada e novos preceitos foram adicionados à discussão sobre os modelos de administração escolar e também por tratar-se de um ensaio, a leitura torna-se importante para quem almeje introduzir seus estudos nesta área, uma vez que a despeito de não avançar tanto nos debates do campo, é leitura relevante como introdução à reflexão sobre as configurações históricas e analíticas da gestão escolar.
Resumos de Dissertações e Teses

\section{Projetos nas escolas do município de Araucária:}

uma política de secundarização da especificidade do trabalho escolar.

Autora: Cristina Cardoso Nível: Mestrado (PPGE-UFPR) Orientadora: Taís Moura Tavares

Resumo:

O presente estudo teve como objetivo principal analisar os projetos implantados nas escolas municipais de Araucária e qual o seu impacto no trabalho delas. Para tanto, foram utilizadas análises de documentos ligados direta e indiretamente com o tema investigado e entrevistas. A presença de projetos nas escolas demonstrou que, entre outros determinantes, estes também, e significativamente, promovem a fragmentação do trabalho pedagógico,

visto que descentralizam a centralidade da função social da escola: o acesso aos conteúdos do conhecimento erudito. Além do que, são resultado de uma pulverização das políticas públicas, que substituem o planejamento por uma lista de projetos para ações pontuais e abrem espaço para a atuação de empresas e/ou Organizações Não Governamentais na escola, com interesses antagônicos aos dos filhos da classe trabalhadora 